\title{
One Pot Enzymatic Production of Nigerose from Common Sugar Resources Employing Nigerose Phosphorylase
}

(Received January 15, 2014; Accepted April 3, 2014)

(J-STAGE Advance Published Date: April 11, 2014)

\author{
Takanori Nihira, ${ }^{1}$ Futaba Miyajima, ${ }^{2}$ Kazuhiro Chiku, ${ }^{2}$ Mamoru Nishimoto, ${ }^{3}$ \\ Motomitsu Kitaoka, ${ }^{3}$ Ken'ichi Ohtsubo ${ }^{1,2}$ and Hiroyuki Nakai ${ }^{1,2, *}$ \\ ${ }^{1}$ Graduate School of Science and Technology, Niigata University \\ (8050 Ikarashi 2-no-cho, Nishi-ku, Niigata. Niigata 950-2181, Japan) \\ ${ }^{2}$ Faculty of Agriculture, Niigata University \\ (8050 Ikarashi 2-no-cho, Nishi-ku, Niigata. Niigata 950-2181, Japan) \\ ${ }^{3}$ National Food Research Institute, National Agriculture and Food Research Organization \\ (2-1-12 Kannondai, Tsukuba, Ibaraki 305-8642, Japan)
}

\begin{abstract}
One-pot enzymatic production of nigerose was demonstrated from abundantly available sugar resources, including maltose, cellobiose, sucrose and starch. (i) $319 \mathrm{mM}$ nigerose was generated from 500 $\mathrm{mM}$ maltose by the combined actions of maltose phosphorylase and nigerose phosphorylase, which share the same $\beta$-D-glucose 1-phosphate, in the presence of phosphate. The yield was $62 \%$ based on the concentration of maltose as the starting material. (ii) $129 \mathrm{mM}$ nigerose was produced from $250 \mathrm{mM}$ cellobiose by cellobiose phosphorylase and nigerose phosphorylase in the presence of phosphate, in combination with the enzymatic pathway to convert $\alpha$-D-glucose 1-phosphate to $\beta$-D-glucose 1 -phosphate via $D$-glucose 6-phosphate by the combined actions of $\alpha$-phosphoglucomutase and $\beta$-phosphoglucomutase, resulting in a yield of $52 \%$. (iii) $350 \mathrm{mM}$ nigerose was produced from $500 \mathrm{mM}$ sucrose by substituting cellobiose phosphorylase with sucrose phosphorylase and adding xylose isomerase, giving a yield of $67 \%$. (iv) $270 \mathrm{mM}$ nigerose was generated from $100 \mathrm{mg} / \mathrm{mL}$ starch and $500 \mathrm{mM}$ D-glucose by the concomitant actions of glycogen phosphorylase, isoamylase, $\alpha$-phosphoglucomutase, $\beta$-phosphoglucomutase and nigerose phosphorylase, in the presence of phosphate. In addition, $280 \mathrm{mM}$ 3-O- $\alpha$-D-glucopyranosyl-D-galactose was produced by substituting D-glucose with D-galactose. Based on the concentrations of D-glucose and Dgalactose as the starting materials, the yields were calculated to be 52 and $56 \%$, respectively. These one-pot enzymatic approaches can be extended to include practical production of a variety of oligosaccharides by substituting nigerose phosphorylase with other $\beta$-D-glucose 1-phosphate-forming phosphorylases together with various carbohydrate acceptors.
\end{abstract}

Key words: nigerose, maltose, sucrose, soluble starch, nigerose phosphorylase, reversible phosphorolysis

\section{INTRODUCTION}

Phosphorylases are exo-lytic enzymes that catalyze phosphorolysis of particular oligosaccharides to produce sugar 1-phosphate with strict substrate specificity. ${ }^{1-3)}$ The reaction is reversible, allowing synthesis of the oligosaccharides from the corresponding sugar 1-phosphate and suitable carbohydrate acceptors with strict regioselectivity. ${ }^{1-3)}$ In addition, the reversibility enables practical production of the oligosaccharides from abundantly available natural sugars without the addition of costly sugar 1-phosphate, using single phosphorylases ${ }^{1,4,5)}$ or by the combined actions of two phosphorylases that share the same sugar 1-phosphate. ${ }^{1,6-10)}$ Recently we developed practical methods to produce $\beta$-D-galactosides, which include lacto- $N$-biose (Bifidus factor in human milk), from sucrose by the combined actions of sucrose phosphorylase (EC 2.4.1.7) and $\alpha$-D-galactose 1-phosphate-forming phosphorylases

* Corresponding author (Tel. +81-25-262-6692; Fax. +81-25-262-6692; E-mail: nakai@agr.niigata-u.ac.jp). together with the enzymatic system to convert $\alpha$-D-glucose 1-phosphate to $\alpha$-D-galactose 1-phosphate, using UDP-glucosehexose 1-phosphate uridylyltransferase (EC 2.7.7.12) and UDP-glucose 4-epimerase (EC 5.1.3.2). ${ }^{11-13)}$ Furthermore, we succeeded in producing 4-O- $\beta$-D-mannopyranosyl- $N$-acetylD-glucosamine (core structure of $\mathrm{N}$-glycans) from sucrose by the combined actions of sucrose phosphorylase and $4-O-\beta$-mannosyl- $N$-acetyl-glucosamine phosphorylase (EC 2.4.1.-) together with the enzymes necessary to convert $\alpha$-D-glucose 1-phospate to $\alpha$-D-mannose 1-phosphate [ $\alpha$-phosphoglucomutase (EC 5.4.2.2), glucose 6-phosphate isomerase (EC 5.3.1.9), mannose 6-phosphate isomerase (EC 5.3.1.8) and phosphomannomutase (EC 5.4.2.8)].14) Thus, phosphorylases may be suitable as catalysts for the practical production of oligosaccharides.

In this study, we report one-pot enzymatic production of nigerose (3-O- $\alpha$-D-glucopyranosyl-D-glucose) from common sugar resources such as maltose, cellobiose, sucrose and soluble starch by nigerose phosphorylase (EC 2.4.1.279), a unique phosphorylase we recently discovered that acts reversibly on 
nigerose to produce $\beta$-D-glucose 1-phosphate and D-glucose, ${ }^{15)}$ together with the enzymatic pathway to convert $\alpha$-D-glucose 1 -phosphate to $\beta$-D-glucose 1-phosphate via D-glucose 6-phosphate by the combined actions of $\alpha$-phosphoglucomutase (EC 5.4.2.2) and $\beta$-phosphoglucomutase (EC 5.4.2.6).

\section{MATERIALS AND METHODS}

Carbohydrates. D-Glucose, maltose monohydrate and soluble starch were purchased from Nacalai Tesque, Inc. (Kyoto, Japan). $\alpha$-D-Glucose 1,6-bisphosphate potassium salt hydrate and D-galactose were purchased from Sigma-Aldrich Corp. (St. Louis, USA). Cellobiose and sucrose were purchased from Tokyo Chemical Industry Co., Ltd. (Tokyo, Japan) and Wako Pure Chemical Industries, Ltd. (Osaka, Japan), respectively.

Enzymes. Nigerose phosphorylase (GenBank ID: ABX42243.1) from Clostridium phytofermentans, cellobiose phosphorylase (GenBank ID: BAA28631.1) from Cellvibrio gilvus and sucrose phosphorylase (GenBank ID: BAJ65776.1) from Bifidobacterium longum JCM1217 were prepared as previously described. ${ }^{11,15,16)}$ Maltose phosphorylase from bacteria, $\beta$-glucosidase from almond and glucoamylase from Rhizopus sp. were purchased from Oriental Yeast Co., Ltd. (Tokyo, Japan). $\beta$-Phosphoglucomutase from Lactococcus sp., isoamylase from Pseudomonas sp. and invertase from Saccharomyces cerevisiae were purchased from Sigma-Aldrich. Xylose isomerase from Streptomyces rubiginosus was purchased from Hampton Research Corp. (Aliso Viejo, USA). $\alpha$-Phosphoglucomutase from Thermococcus kodakarensis KOD1 (GenBank ID: BAD85297.1) and glycogen phosphorylase from Thermotoga maritima MSB8 (GenBank ID: AGL50099.1)were prepared as described in previous papers ${ }^{17,18)}$ with several modifications. Escherichia coli BL21 (DE3) and E. coli Rosetta2 (DE3) were transformed with expression plasmids for $\alpha$-phosphoglucomutase and glycogen phosphorylase genes, respectively, which were inserted into pET-30a and pET-24a, respectively, between NdeI and XhoI sites. Recombinant proteins were purified using previously described methods for His-tag fusion proteins. ${ }^{14)}$ The protein concentrations of $\alpha$-phosphoglucomutase and glycogen phosphorylase were determined spectrophotometrically at $280 \mathrm{~nm}$ using theoretical extinction coefficients of $\varepsilon=$ 26,930 and $151,150 \mathrm{M}^{-1} \mathrm{~cm}^{-1}$, respectively, based on the amino acid sequences. ${ }^{19)}$

Enzyme activity. Reverse phosphorolytic activity of nigerose phosphorylase was determined by methods described previously. ${ }^{15)}$ Phosphorolytic activities of $\alpha$-D-glucose 1-phosphateforming phosphorylases were routinely determined by quantifying $\alpha$-D-glucose 1-phosphate released from the corresponding substrate $(10 \mathrm{mM}$ cellobiose for cellobiose phosphorylase, $10 \mathrm{mM}$ sucrose for sucrose phosphorylase or $10 \mathrm{mg} / \mathrm{mL}$ soluble starch for glycogen phosphorylase) in $40 \mathrm{mM}$ HEPES-NaOH (pH 7.0) containing $10 \mathrm{mM}$ phosphate at $30^{\circ} \mathrm{C}$ using the phosphoglucomutase-glucose 6-phosphate dehydrogenase method ${ }^{20)}$ as described previously. ${ }^{11,21)} \alpha$-Phosphoglucomutase activity was determined by measuring the increase in D-glucose 6-phosphate ${ }^{22)}$ from $10 \mathrm{mM} \alpha$-D-glucose 1-phosphate in $40 \mathrm{mM}$ HEPES-NaOH buffer ( $\mathrm{pH} 7.0$ ) containing $5.0 \mathrm{U} / \mathrm{mL}$ glucose 6-phosphate dehydrogenase, $0.25 \mathrm{mM}$ thio-NAD ${ }^{+}$, $41 \mu \mathrm{M}$ D-glucose 1,6-bisphosphate and $10 \mathrm{mM} \mathrm{MgCl}_{2}$ at $30^{\circ} \mathrm{C}$. One unit of enzyme was defined as the amount of enzyme that liberated $1 \mu \mathrm{mol}$ product per min under the above conditions. The activities of all commercial enzymes were defined according to the manufacturer's protocol.

Quantification by high performance liquid chromatography (HPLC). The concentrations of reaction products were monitored during the reaction by HPLC (Prominence, Shimadzu, Kyoto, Japan) equipped with an RI detector and a Shodex Asahipak NH2P50-4E column (4.6 mm internal diameter $\times 250 \mathrm{~mm}$, Showa Denko K.K, Tokyo, Japan) at $30^{\circ} \mathrm{C}$ under a constant flow $(1 \mathrm{~mL} / \mathrm{min})$ of mobile phase (acetonitrile/water v/v, 75/25). The one-pot enzymatic reaction was terminated at specific intervals by adding $10 \mu \mathrm{L}$ of the reaction mixture to $90 \mu \mathrm{L}$ of $100 \mathrm{mM} \mathrm{HCl}$, followed by $\mathrm{pH}$ adjustment by $1 \mathrm{M} \mathrm{NaOH}$ (pH 7.0, 5.0, 5.0 or 7.0 for maltose, cellobiose, sucrose and soluble starch, respectively) for enzymatic digestion of the remaining starting materials. The each maltose, cellobiose, sucrose and soluble starch was digested by addition of $85 \mu \mathrm{L}$ of $115 \mu \mathrm{g} / \mathrm{mL}(5 \mathrm{U} / \mathrm{mL})$ glucoamylase, $100 \mu \mathrm{L}$ of $10 \mathrm{mg} / \mathrm{mL}(100 \mathrm{U} / \mathrm{mL}) \beta$-glucosidase, $3.3 \mu \mathrm{L}$ of $10 \mathrm{mg} / \mathrm{mL}(3,000 \mathrm{U} / \mathrm{mL})$ invertase and $85 \mu \mathrm{L}$ of $115 \mu \mathrm{g} / \mathrm{mL}$ (5 U/mL) glucoamylase, respectively, at $30^{\circ} \mathrm{C}$ overnight.

Purification by gel-filtration chromatography. After a $216 \mathrm{~h}$ reaction, $9 \mathrm{~mL}$ of $100 \mathrm{mM} \mathrm{HCl}$ was added to the reaction mixture to stop the one-pot enzymatic reaction, followed by $\mathrm{pH}$ adjustment by $1 \mathrm{M} \mathrm{NaOH}(\mathrm{pH} 7.0,5.0,5.0$ or 7.0 for maltose, cellobiose, sucrose and soluble starch, respectively). The remaining maltose, cellobiose, sucrose and soluble starch were digested by addition of $23 \mu \mathrm{L}$ of $23 \mathrm{mg} / \mathrm{mL}(1,000 \mathrm{U} /$ $\mathrm{mL})$ glucoamylase, $100 \mu \mathrm{L}$ of $505 \mathrm{mg} / \mathrm{mL}(5,050 \mathrm{U} / \mathrm{mL})$ $\beta$-glucosidase, $3.3 \mu \mathrm{L}$ of $10 \mathrm{mg} / \mathrm{mL}(3,000 \mathrm{U} / \mathrm{mL})$ invertase and $23 \mu \mathrm{L}$ of $23 \mathrm{mg} / \mathrm{mL}(1,000 \mathrm{U} / \mathrm{mL})$ glucoamylase, respectively, at $30^{\circ} \mathrm{C}$ overnight. After heat treatment at $60^{\circ} \mathrm{C}$ for 30 min to inactivate the added glucoamylase, $\beta$-glucosidase or invertase, the supernatant collected by centrifugation at $10,000 \times \mathrm{G}$ for $20 \mathrm{~min}$ was concentrated by a centrifugal evaporator (CVE-3100, Tokyo Rikakikai Co., Ltd, Tokyo, Japan). The concentrated sample was applied to a Toyopearl HW40S column $(50 \mathrm{~mm}$ internal diameter $\times 90 \mathrm{~cm}$; Tosoh Corp., Tokyo, Japan) equilibrated with Milli-Q water (Merck Millipore Corp., Billerica, USA), followed by elution at a flow rate of $1.0 \mathrm{~mL} / \mathrm{min}$ using ÄKTA prime (GE Healthcare Limited, Buckinghamshire, UK). The elution patterns of the products in the gel filtration chromatography were monitored using thin layer chromatography (TLC) (Kieselgel 60 F254, Merck Millipore Corp.), developed by acetonitrile/water (v/v, 80/20). The TLC plates were soaked in 5\% sulfuric acid-methanol solution and heated in an oven until the bands were visible. Fractions containing nigerose or 3-O- $\alpha$-D-glucopyranosyl-Dgalactose were collected, followed by lyophilization. ${ }^{1} \mathrm{H}-\mathrm{NMR}$ spectra of the products were acquired in $\mathrm{D}_{2} \mathrm{O}$ using a Bruker DMX 600 spectrometer (Bruker Biospin GmbH, Rheinstetten, Germany). The structures of isolated products were confirmed by comparing ${ }^{1} \mathrm{H}-\mathrm{NMR}$ data with that of authentic nigerose and 3-O- $\alpha$-D-glucopyranosyl-D-galactose standards. ${ }^{15)}$

\section{RESULTS AND DISCUSSION}

The reaction scheme for production of nigerose from maltose is shown in Fig. 1 (A). In the reaction, maltose is phosphorolyzed by maltose phosphorylase into $\beta$-D-glucose 
1-phosphate and D-glucose. The resulting products are continuously converted by nigerose phosphorylase to nigerose and phosphate. Because the phosphate is recycled during the reaction, the overall reaction is described as the transformation of maltose to nigerose in the presence of catalytic amounts of phosphate by the combined actions of the two phosphorylases that share the same sugar 1-phosphate. The one-pot enzymatic synthesis of nigerose was demonstrated in a reaction mixture $(1 \mathrm{~mL})$ containing $500 \mathrm{mM}$ maltose, various concentrations $(1-100 \mathrm{mM})$ of sodium phosphate buffer (pH 7.0), $27 \mu \mathrm{g} / \mathrm{mL}(0.30 \mathrm{U} / \mathrm{mL})$ maltose phosphorylase and $20 \mu \mathrm{g} / \mathrm{mL}(0.62 \mathrm{U} / \mathrm{mL})$ nigerose phosphorylase at $30^{\circ} \mathrm{C}$. We examined the optimum concentration of the phosphate in the reaction mixture $(\mathrm{pH}$ 7.0: the optimum $\mathrm{pH}$ of reverse phosphorolysis using $\beta$-D-glucose 1-phosphate and D-glucose by nigerose phosphorylase), resulting that no significant effect

Table 1. One-pot enzymatic syntheses of nigerose and its derivative.

\begin{tabular}{|c|c|c|c|}
\hline Starting material & Acceptor & Product & $\begin{array}{l}\text { Yield } \\
(\%)\end{array}$ \\
\hline $500 \mathrm{mM}$ Maltose & - & Nigerose & $62^{\mathrm{a}}$ \\
\hline $250 \mathrm{mM}$ Cellobiose & - & Nigerose & $52^{\mathrm{a}}$ \\
\hline $500 \mathrm{mM}$ Sucrose & - & Nigerose & $67^{\mathrm{a}}$ \\
\hline $\begin{array}{l}100 \mathrm{mg} / \mathrm{mL} \\
\text { Soluble starch }\end{array}$ & $\begin{array}{c}500 \mathrm{mM} \\
\text { D-Glucose }\end{array}$ & Nigerose & $52^{\mathrm{b}}$ \\
\hline $\begin{array}{l}100 \mathrm{mg} / \mathrm{mL} \\
\text { Soluble starch }\end{array}$ & $\begin{array}{c}500 \mathrm{mM} \\
\text { D-Galactose }\end{array}$ & $\begin{array}{c}\text { 3-O- } \alpha \text {-D-Glucosyl- } \\
\text { D-galactose }\end{array}$ & $56^{\mathrm{b}}$ \\
\hline
\end{tabular}

${ }^{a}$ The yields were calculated based on the concentrations of the starting materials. ${ }^{b}$ The yields were calculated based on the concentrations of the acceptors.

A

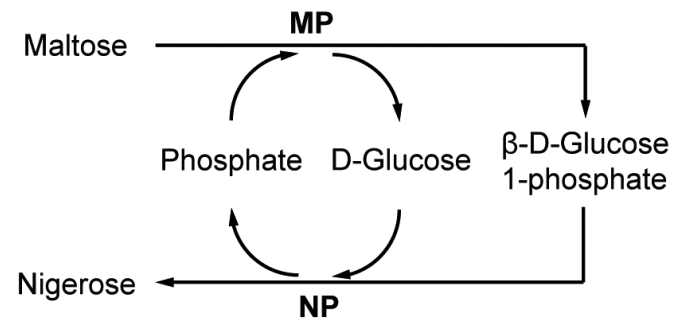

B

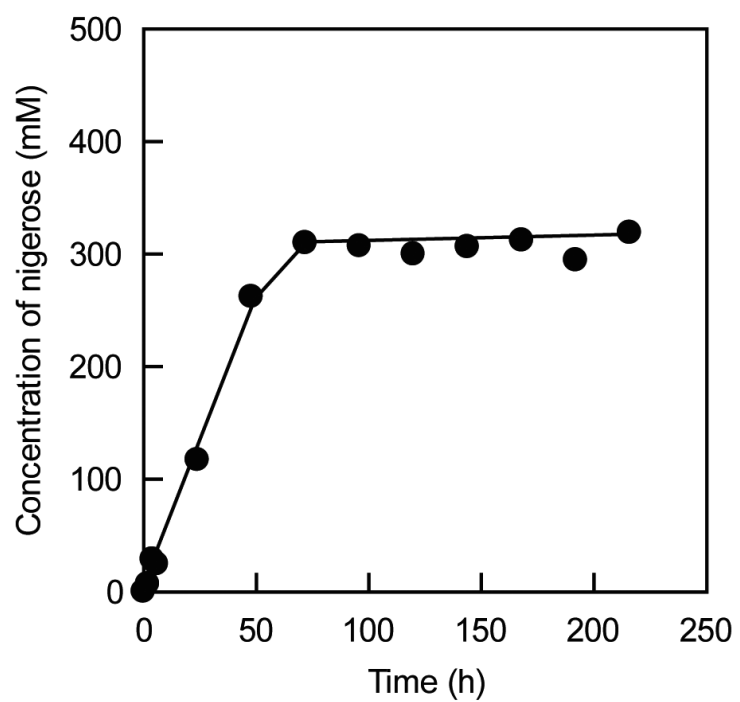

Fig. 1. Production of nigerose from maltose.

(A) The reaction scheme for one-pot enzymatic production of nigerose from maltose. MP, maltose phosphorylase; NP, nigerose phosphorylase. (B) Time course of nigerose production from maltose. on the concentration of nigerose were observed with increase in that of phosphate. As shown in Fig. 1(B), the concentration of nigerose in the reaction mixture reached $310 \mathrm{mM}$ at $72 \mathrm{~h}$. The reaction yield was $62 \%$ based on the concentration of maltose used as the starting material (Table 1). The produced nigerose was purified by gel-filtration column chromatography, and it yielded $109 \mathrm{mg}$ lyophilized nigerose.

We also produced nigerose from cellobiose by cellobiose phosphorylase and nigerose phosphorylase together with the enzymatic system to convert $\alpha$-D-glucose 1-phosphate to $\beta$-D-glucose 1-phosphate (Fig. 2(A)). The one-pot enzymatic synthesis of nigerose was demonstrated in a reaction mixture (1 mL) containing $250 \mathrm{mM}$ cellobiose, $25 \mathrm{mM}$ sodium phosphate buffer (pH 7.0), $10 \mathrm{mM} \mathrm{MgCl}_{2}, \quad 41 \mu \mathrm{M}$ $\alpha$-D-glucose 1,6-bisphosphate, $2.3 \mathrm{mg} / \mathrm{mL} \quad(0.63 \mathrm{U} / \mathrm{mL})$ cellobiose phosphorylase, $\quad 420 \mu \mathrm{g} / \mathrm{mL} \quad(0.25 \mathrm{U} / \mathrm{mL})$ $\alpha$-phosphoglucomutase, $\quad 210 \mu \mathrm{g} / \mathrm{mL} \quad(5.0 \mathrm{U} / \mathrm{mL})$ $\beta$-phosphoglucomutase and $20 \mu \mathrm{g} / \mathrm{mL}(0.62 \mathrm{U} / \mathrm{mL})$ nigerose phosphorylase at $30^{\circ} \mathrm{C}$. In the reaction, cellobiose is first phosphorolyzed by cellobiose phosphorylase into $\alpha$-D-glucose 1 -phosphate and D-glucose. The resulting $\alpha$-D-glucose 1 -phosphate is continuously converted into $\beta$-D-glucose 1-phosphate via D-glucose 6-phosphate by the concomitant actions of $\alpha$-phosphoglucomutase and $\beta$-phosphoglucomutase. Finally, nigerose is synthesized from $\beta$-D-glucose 1 -phosphate

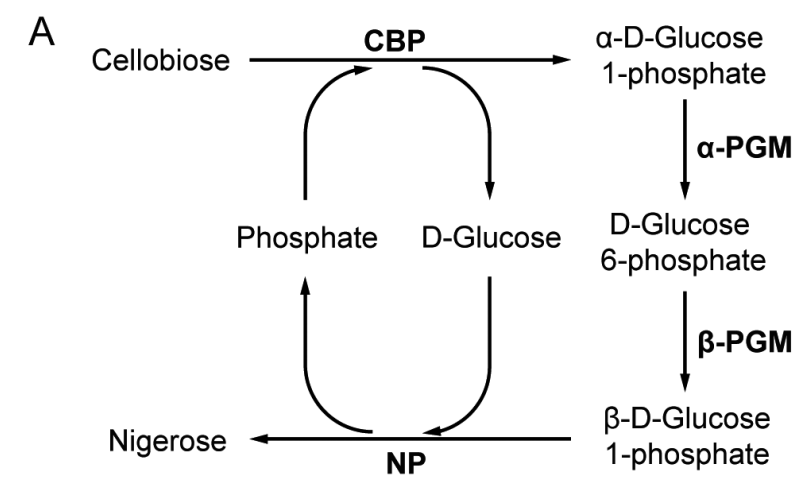

B

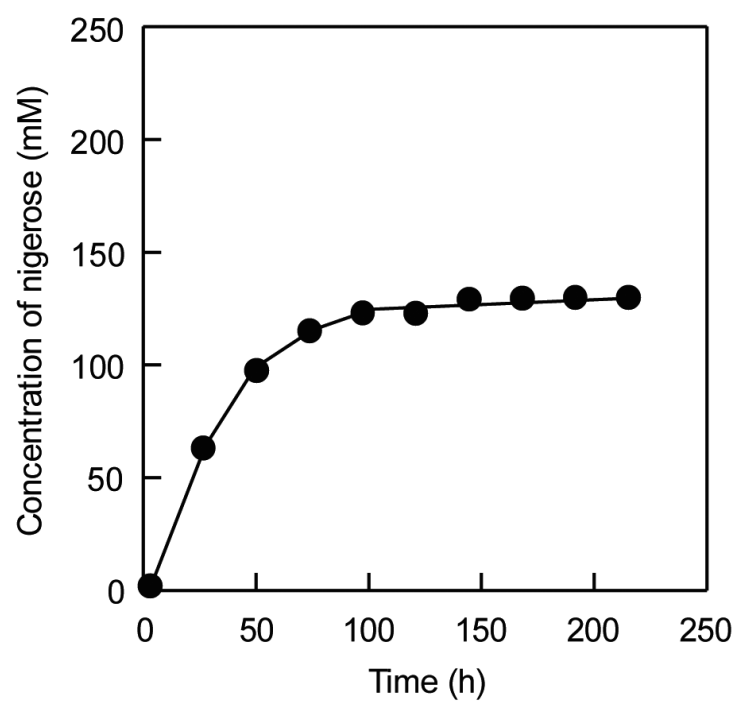

Fig. 2. Production of nigerose from cellobiose.

(A) The reaction scheme for one-pot enzymatic production of nigerose from cellobiose. NP, nigerose phosphorylase; $\alpha-P G M$, $\alpha$-phosphoglucomutase; $\beta$-PGM, $\beta$-phosphoglucomutase; CBP, cellobiose phosphorylase. (B) Time course of nigerose production from cellobiose. 
and D-glucose by nigerose phosphorylase. Because phosphate is recycled during the reaction, the overall reaction is described as the transformation of cellobiose to nigerose. As shown in Fig. 2(B), the concentration of nigerose in the reaction mixture reached $129 \mathrm{mM}$ at $168 \mathrm{~h}$. The reaction yield was $52 \%$ based on the concentration of cellobiose used as the starting material (Table 1). Finally, $44 \mathrm{mg}$ of purified nigerose was recovered by gel-filtration column chromatography and lyophilization.

Production of nigerose from sucrose was also performed using the above one-pot enzymatic approach by substituting cellobiose phosphorylase with sucrose phosphorylase and adding xylose isomerase to convert D-fructose liberated from sucrose by phosphorolysis of sucrose phosphorylase into D-glucose as the acceptor for nigerose synthesis (Fig. 3(A)). The production of nigerose was demonstrated in a reaction mixture ( $1 \mathrm{~mL}$ ) containing $500 \mathrm{mM}$ sucrose, $10 \mathrm{mM} \mathrm{MgCl}_{2}$, $41 \mu \mathrm{M} \alpha$-D-glucose 1,6-bisphosphate, various concentrations (1-100 mM) of sodium phosphate buffer ( $\mathrm{pH} 7.0), 9.1$ or $91 \mu \mathrm{g} / \mathrm{mL}(0.73$ or $7.3 \mathrm{U} / \mathrm{mL})$ sucrose phosphorylase, 33 or $330 \mu \mathrm{g} / \mathrm{mL}(0.73$ or $7.3 \mathrm{U} / \mathrm{mL})$ xylose isomerase, 420 or $4,200 \mu \mathrm{g} / \mathrm{mL}(0.25$ or $2.5 \mathrm{U} / \mathrm{mL}) \alpha$-phosphoglucomutase, 21 or $210 \mu \mathrm{g} / \mathrm{mL}(0.5$ or $5.0 \mathrm{U} / \mathrm{mL}) \beta$-phosphoglucomutase and 20 or $200 \mu \mathrm{g} / \mathrm{mL}$ (0.62 or $6.2 \mathrm{U} / \mathrm{mL}$ ) nigerose phosphorylase at $30^{\circ} \mathrm{C}$. The optimum starting composition of the reaction mixture was determined to be $500 \mathrm{mM}$ sucrose, $10 \mathrm{mM}$ $\mathrm{MgCl}_{2}, 41 \mu \mathrm{M} \alpha$-D-glucose 1,6-bisphosphate, $25 \mathrm{mM}$ sodium phosphate buffer ( $\mathrm{pH} 7.0), 9.1 \mu \mathrm{g} / \mathrm{mL}(0.73 \mathrm{U} / \mathrm{mL})$ sucrose phosphorylase, $330 \mu \mathrm{g} / \mathrm{mL}(7.3 \mathrm{U} / \mathrm{mL})$ xylose isomerase, $420 \mu \mathrm{g} / \mathrm{mL}(0.25 \mathrm{U} / \mathrm{mL}) \alpha$-phosphoglucomutase, $210 \mu \mathrm{g} / \mathrm{mL}$ (5.0 U/mL) $\beta$-phosphoglucomutase and $20 \mu \mathrm{g} / \mathrm{mL}(0.62 \mathrm{U} /$ $\mathrm{mL}$ ) nigerose phosphorylase. Under the optimum conditions, the concentration of nigerose in the reaction mixture reached $335 \mathrm{mM}$ at $72 \mathrm{~h}$, indicating a reaction yield of $67 \%$ based on the concentration of sucrose used as the starting material (Fig. 3 (B), Table 1). Finally, $120 \mathrm{mg}$ of purified nigerose was recovered by gel-filtration column chromatography and lyophilization.

Nigerose was also produced from starch as the starting material (Fig. 4(A)). In the reaction, soluble starch is phosphorolyzed by glycogen phosphorylase together with hydrolysis of $\alpha-1,6$-glucosidic linkages by isoamylase to liberate $\alpha$-D-glucose 1 -phosphate, which is continuously converted into $\beta$-D-glucose 1-phosphate via glucose 6-phosphate by the concomitant actions of $\alpha$-phosphoglucomutase and $\beta$-phosphoglucomutase. The resulting $\beta$-D-glucose 1-phosphate is consumed together with D-glucose by nigerose phosphorylase to produce nigerose and phosphate, which is recycled for phosphorolysis of soluble starch during the reaction. The one-pot enzymatic synthesis of nigerose was demonstrated in a reaction mixture (1 mL) containing $100 \mathrm{mg} / \mathrm{mL}$ soluble starch, $500 \mathrm{mM}$ D-glucose, various concentrations $(1-100 \mathrm{mM})$ of sodium phosphate buffer ( $\mathrm{pH} 7.0), 10 \mathrm{mM} \mathrm{MgCl} 2,41 \mu \mathrm{M} \alpha$-D-glucose 1,6-bisphosphate, $960 \mu \mathrm{g} / \mathrm{mL} \quad(0.026 \mathrm{U} / \mathrm{mL})$ glycogen phosphorylase, $\quad 0.33 \mu \mathrm{g} / \mathrm{mL} \quad(17 \mathrm{U} / \mathrm{mL})$ isoamylase (EC 3.2.1.68), $420 \mu \mathrm{g} / \mathrm{mL}(0.3 \mathrm{U} / \mathrm{mL}) \alpha$-phosphoglucomutase, $210 \mu \mathrm{g} / \mathrm{mL}(5.0 \mathrm{U} / \mathrm{mL}) \beta$-phosphoglucomutase and $20 \mu \mathrm{g} / \mathrm{mL}$ $(0.62 \mathrm{U} / \mathrm{mL})$ nigerose phosphorylase at $30^{\circ} \mathrm{C}$. The optimum concentration of the phosphate was determined to be $75 \mathrm{mM}$, resulting that the concentration of nigerose in the reaction mixture reached $259 \mathrm{mM}$ at $192 \mathrm{~h}$ (Fig. 4(B)). The reaction yield was $52 \%$ based on the concentration of D-glucose used
(Table 1). Finally, $90 \mathrm{mg}$ of purified nigerose was recovered by gel-filtration column chromatography and lyophilization. In addition, several nigerose derivatives can be synthesized by reverse phosphorolysis of nigerose phosphorylase by substituting D-glucose with suitable monosaccharide acceptors. ${ }^{15)}$ Therefore, the one-pot enzymatic approach using soluble starch as the starting material was applied to synthesize a nigerose derivative, 3-O- $\alpha$-D-glucopyranosyl-D-galactose, by substituting $500 \mathrm{mM}$ D-glucose with $500 \mathrm{mM}$ D-galactose, resulting that the concentration of 3-O- $\alpha$-D-glucopyranosyl-D-galactose in the reaction mixture reached $280 \mathrm{mM}$ at $168 \mathrm{~h}$ in a yield of $56 \%$ based on the concentration of D-galactose used. Finally, $96 \mathrm{mg}$ of purified 3-O- $\alpha$-D-glucopyranosyl-D-galactose was obtained.

Nigerose is a constitutional unit of $\alpha-1,3$-polysaccharides such as nigeran, pseudonigeran and isolichenin produced by filamentous fungi such as the genus Aspergillus. ${ }^{23)}$ It has been also found in beer and Japanese rice wine ${ }^{24)}$ and has been reported to show anticaries ${ }^{25}$ and immunostimulatory activity. ${ }^{26)}$ It would therefore be beneficial to develop efficient production methods of nigerose as a functional oligosaccharide. Nigerose can be enzymatically synthesized from sucrose and D-glucose by transglycosylation of sucrose phosphorylase. ${ }^{27)}$ In addition, nigerooligosaccharides including nigerose, nigerosylglucose ( $\alpha$-D-glucopyranosyl-1,3- $\alpha$-D-glucopyranosyl-1,4- $\alpha$-D-

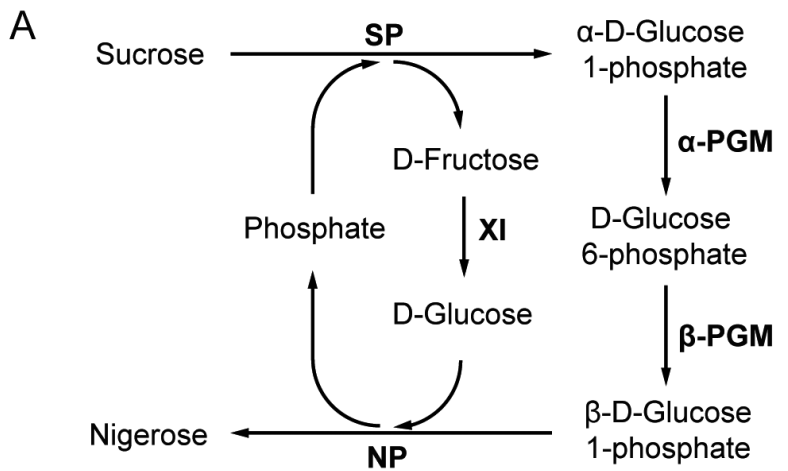

B

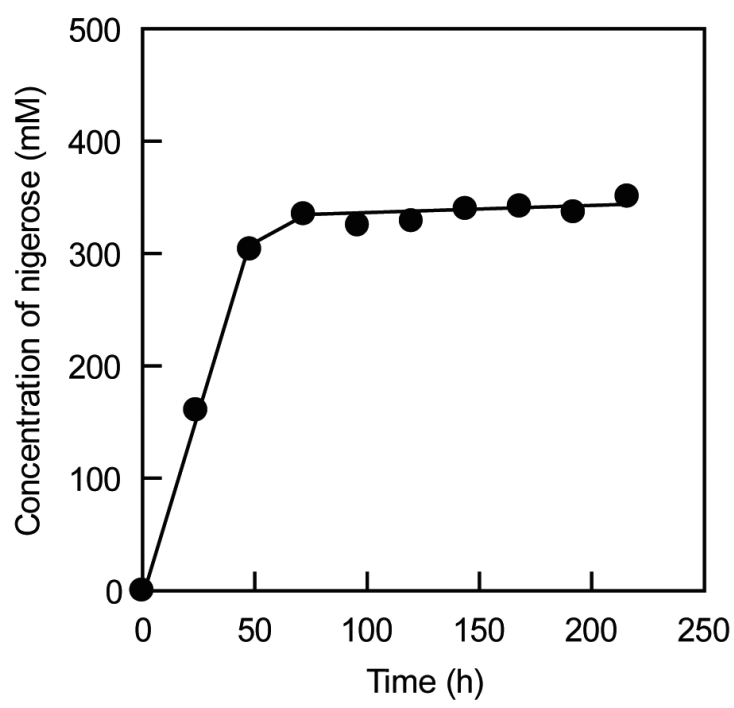

Fig. 3. Production of nigerose from sucrose.

(A) The reaction scheme for one-pot enzymatic production of nigerose from sucrose. NP, nigerose phosphorylase; $\alpha-P G M$, $\alpha$-phosphoglucomutase; $\beta$-PGM, $\beta$-phosphoglucomutase; SP, sucrose phosphorylase; XI, xylose isomerase. (B) Time course of nigerose production from sucrose. 
A

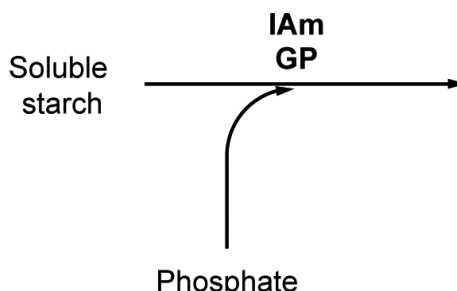

a-D-Glucose

1-phosphate a-PGM

D-Glucose

6-phosphate

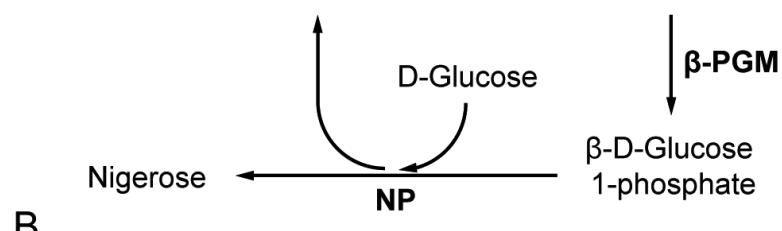

B

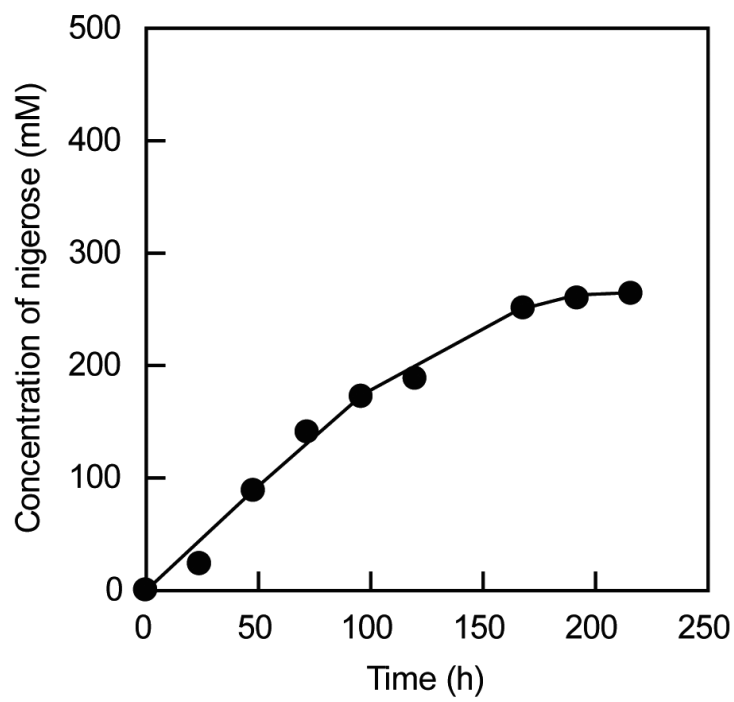

Fig. 4. Production of nigerose from soluble starch.

(A) The reaction scheme for one-pot enzymatic production of nigerose from soluble starch. GP, glycogen phosphorylase; IAm, isoamylase; NP, nigerose phosphorylase; $\alpha$-PGM, $\alpha$-phosphoglucomutase; $\beta$-PGM, $\beta$-phosphoglucomutase. (B) Time course of nigerose production from soluble starch.

glucose) and nigerosylmaltose ( $\alpha$-D-glucopyranosyl-1,3- $\alpha$ D-glucopyranosyl-1,4- $\alpha$-D-glucopyranosyl-1,4- $\alpha$-Dglucose) are produced from maltose by transglycosylation of Acremonium sp. $\alpha$-glucosidase (EC 3.2.1.20). ${ }^{28)}$ The one-pot enzymatic approach developed in this study is an alternative method for production of nigerose from inexpensive sugars. It should be noted that the synthetic method can be extended to include the practical production of a variety of oligosaccharides by substituting nigerose phosphorylase with other $\beta$-D-glucose 1-phosphate-forming phosphorylases together with various carbohydrate acceptors.

\section{ACKNOWLEDGMENTS}

This work was supported in part by the MEXT program "Promotion of Environmental Improvement for Independence of Young Researchers" under the Special Coordination Funds for Promoting Science and Technology, research grant from the Kato Memorial Bioscience Foundation and the Tojuro Iijima Foundation for Food Science and Technology, Adaptable and Seamless Technology Transfer Program through target-driven R\&D from Japan Science and Technology Agency, Science and Technology Research Promotion Program for Agriculture, Forestry, Fisheries and Food Industry.

\section{REFERENCES}

1 ) M. Kitaoka and K. Hayashi: Carbohydrate-processing phospho- rolytic enzymes. Trends Glycosci. Glycotechnol., 14, 35-50 (2002).

2 ) C. Luley-Goedl and B. Nidetzky: Carbohydrate synthesis by disaccharide phosphorylases: Reactions, catalytic mechanisms and application in the glycosciences. Biotechnol. J., 5, 1324-1338 (2010).

3 ) H. Nakai, M. Kitaoka, B. Svensson and K. Ohtsubo: Recent development of phosphorylases possessing large potential for oligosaccharide synthesis. Curr. Opin. Chem. Biol., 17, 301-309 (2013).

4 ) T. Sawangwan, C. Goedl and B. Nidetzky: Single-step enzymatic synthesis of (R)-2-O- $\alpha$-D-glucopyranosyl glycerate, a compatible solute from micro-organisms that functions as a protein stabiliser. Org. Biomol. Chem., 7, 4267-4270 (2009).

5 ) H. Nakai, A. Dilokpimol, M. Abou Hachem and B. Svensson: Efficient one-pot enzymatic synthesis of $\alpha-(1 \rightarrow 4)$-glucosidic disaccharides through a coupled reaction catalysed by Lactobacillus acidophilus NCFM maltose phosphorylase. Carbohydr. Res., 345, 1061-1064 (2010).

$6)$ S. Murao, H. Nagano, S. Ogura and T. Nishino: Enzymatic synthesis of trehalose from maltose. Agric. Biol. Chem., 49, 2113-2118 (1985).

7 ) H. Chaen, T. Nishimoto, T. Nakada, S. Fukuda, M. Kurimoto and Y. Tsujisaka: Enzymatic synthesis of kojioligosaccharides using kojibiose phosphorylase. J. Biosci. Bioeng., 92, 177-182 (2001).

8 ) M. Suzuki, K. Kaneda, Y. Nakai, M. Kitaoka and H. Taniguchi: Synthesis of cellobiose from starch by the successive actions of two phosphorylases. New Biotechnol., 26, 137-142 (2009).

9 ) K. Ohdan, K. Fujii, M. Yanase, T. Takaha and T. Kuriki: Enzymatic synthesis of amylose. Biocatal. Biotransform., 24, 77-81 (2006).

10) K. Ohdan, K. Fujii, M. Yanase, T. Takaha and T. Kuriki: Phosphorylase coupling as a tool to convert cellobiose into amylose. $J$. Biotechnol., 127, 496-502 (2007).

11) M. Nishimoto and M. Kitaoka: Practical preparation of lacto- $N$ biose I, a candidate for the bifidus factor in human milk. Biosci. Biotechnol. Biochem., 71, 2101-2104 (2007).

12) M. Nishimoto and M. Kitaoka: One-pot enzymatic production of $\beta$-D-galactopyranosyl-( $(1 \rightarrow 3)$-2-acetamido-2-deoxy-D-galactose (galacto- $N$-biose) from sucrose and 2-acetamido-2-deoxy-D-galactose ( $N$-acetylgalactosamine). Carbohydr. Res., 344, 2573-2576 (2009).

13) M. Nakajima, M. Nishimoto and M. Kitaoka: Practical preparation of D-galactosyl- $\beta 1 \rightarrow 4$-L-rhamnose employing the combined action of phosphorylases. Biosci. Biotechnol. Biochem., 74, 1652-1655 (2010).

14) T. Nihira, E. Suzuki, M. Kitaoka, M. Nishimoto, K. Ohtsubo and H. Nakai: Discovery of $\beta$-1,4-D-mannosyl- $N$-acetyl-D-glucosamine phosphorylase involved in the metabolism of $N$-glycans. J. Biol. Chem., 288, 27366-27374 (2013).

15) T. Nihira, H. Nakai, K. Chiku and M. Kitaoka: Discovery of nigerose phosphorylase from Clostridium phytofermentans. Appl. Microbiol. Biotechnol., 93, 1513-1522 (2012).

16) A. Liu, H. Tomita, H. Li, H. Miyaki, C. Aoyagi, S. Kaneko and K. Hayashi: Cloning, sequencing and expression of the cellobiose phosphorylase gene of Cellvibrio gilvus. J. Ferment. Bioeng., 85, 511-513 (1998).

17) N. Rashid, T. Kanai, H. Atomi and T. Imanaka: Among multiple phosphomannomutase gene orthologues, only one gene encodes a protein with phosphoglucomutase and phosphomannomutase activities in Thermococcus kodakaraensis. J. Bacteriol., 186, 6070-6076 (2004).

18) M. Bibel, C. Brettl, U. Gosslar, G. Kriegshäuser and W. Liebl: Isolation and analysis of genes for amylolytic enzymes of the hyperthermophilic bacterium Thermotoga maritima. FEMS Microbiol. Lett., 158, 9-15 (1998).

19) C.N. Pace, F. Vajdos, L. Fee, G. Grimsley and T. Gray: How to measure and predict the molar absorption coefficient of a protein. Protein Sci., 4, 2411-2423 (1995)

20) G. Michal: D-Glucose 1-phosphate. in Method of Enzymatic Analysis Vol. 6, H.U. Bergmeyer, J. Bergmeyer and M. Grassl, eds, 3rd Ed., Verlag Chemie, Weinheim, pp. 185-191 (1984).

21) M. Kitaoka, Y. Matsuoka, K. Mori, M. Nishimoto and K. Hayashi: Characterization of a bacterial laminaribiose phosphorylase. 
Biosci. Biotechnol. Biochem., 76, 343-348 (2012).

22) G. Lang and G. Michal: D-Glucose-6 phosphate and D-fructose-6 phosphate. in Methods of Enzymatic Analysis Vol. 3, H.U. Bergmeyer, eds, 2nd Ed., Verlag Chemie, Weinheim, pp. 1238-1242 (1974).

23) S.A. Barker and T.R. Carrington: Studies of Aspergillus niger. Part II. Transglycosidation by Aspergillus niger. J. Chem. Soc., 3588-3593 (1953).

24) I.R. Siddiqui: The sugars of honey. Adv. Carbohydr. Chem. Biochem., 25, 285-309 (1971).

25) S. Imai, K. Takeuchi, K. Shibata, S. Yoshikawa, S. Kitahata, S. Okada, S. Araya and T. Nisizawa: Screening of sugars inhibitory against sucrose-dependent synthesis and adherence of insoluble glucan and acid production by Streptococcus mutans. J. Dent. Res., 63, 1293-1297 (1984)

26) S. Murosaki, K. Muroyama, Y. Yamamoto, H. Kusaka, T. Liu and Y. Yoshikai: Immunopotentiating activity of nigerooligosaccharides for the T helper 1-like immune response in mice. Biosci. Biotechnol. Biochem., 63, 373-378 (1999).

27) S. Kitao, S. Yoshida, T. Horiuchi, H. Sekine and I. Kusakabe: Formation of kojibiose and nigerose by sucrose phosphorylase. Biosci. Biotechnol. Biochem., 58, 790-791 (1994).

28) Y. Konishi and K. Shindo: Production of nigerose, nigerosyl glucose, and nigerosyl maltose by Acremonium sp. S4G13. Biosci. Biotechnol. Biochem., 61, 439-442 (1997). 